\title{
Modelling of Information Systems of Intelligent Manufacturing Monitoring in Smart Factory
}

\author{
Yu'an He, Tian Chen, Kaiyuan Xu and Zongtang Wu \\ College of Engineering, Shanghai Polytechnic University, Shanghai 201209, China
}

\begin{abstract}
Information monitoring of the intelligent manufacturing plays an important role in smart factory. The construction of efficient information monitoring system is the important basis of manufacturing monitoring. In this paper, three factors of information monitoring system are presented, they are monitoring entity object, information transmission and collection method, and operating mode of monitoring system. Monitoring entity object include material, personnel and equipment. Information collection include three methods, involve in automation equipment collection, manual acquisition and automatic identification technology. Because manufacturing execution system (MES) is good for the intelligent manufacturing monitoring, so the manufacturing monitoring operating mode is proposed based on MES. At last, system model's good application value is achieved.
\end{abstract}

Keyword-Intelligent manufacturing; Monitoring information system; Production process; Smart factory

\section{INTRODUCTION}

High efficient and speed intelligent production mode make the production capacity of enterprises continuously improved, the product process involve in large of manufacturing resources, materials, and technological process. Complex manufacturing system has low management efficiency, backward scheduling, and this system cannot monitor or retrospect quality standards of products in manufacturing process, and it isn't good for the collection of production process data. And most companies still adopt the traditional workshop management style which needs workers to transcribe data manually, and this style do not have ability implement global real-time monitoring for the whole production process, and the system could not adjust to the real time adjustment of production plan.

Aim at the new problems, existing ERP, MES, PDM is not fully suitable to the new problems, a maturing solution is lacking. So, a kind of model of intelligent manufacturing monitoring system is proposed based on internet of things information technology and MES, and the key factors of model are also proposed. The three factors of monitoring system model include production monitoring entity object, special information transfer method and manufacturing monitoring system operation mode based on this kind of information transfer method. The model is able to provide scientific basis for quickly systematically building enterprise monitoring and control system, and laying the groundwork for intelligent and information production.

In the following section, the details of intelligent production monitoring system model is elaborated, and the key factors of monitoring system model is proposed.

\section{ANALYSIS OF INTELLIGENT PRODUCTION MONITORING SYSTEM}

Intelligent production monitoring system model include physical entity and virtual production information in all production system. Three factors include monitoring physical entity, virtual information transmittal mode, and monitoring system operational mode. Then monitoring system operational mode is build based on monitoring physical entity and virtual information transmittal mode. Three core factors of the monitoring system will be exposited as follow.

The essence of the workshop production is the process that worker use tools and equipment to manufacturing products. Workers, tools and products are physical entity, those physical entity finished workshop production, and creating value. Production monitoring aims at keep mastering the location, status and performance of the resources, in order to help administrator to use those information to optimize and configure manufacturing resources scientifically.

Based on the above, analyzing production physical entity, the information monitoring object of workshop production can be divided into three sorts: materials/product, equipment, worker [1], as shown in Table 1.

TABLE I. PHYSICAL ENTITY OF PRODUCTION MONITORING SYSTEM

\begin{tabular}{|l|l|l|}
\hline Object & $\begin{array}{l}\text { Monitoring } \\
\text { Property }\end{array}$ & Monitoring Function \\
\hline Materials & $\begin{array}{l}\text { 1.Materials } \\
\text { running status } \\
\text { 2.Materials } \\
\text { consumption } \\
\text { status }\end{array}$ & $\begin{array}{l}\text { 1.Monitor the actual location of the } \\
\text { material, control the cost of materials; } \\
\text { 2.For abnormal material shortages, } \\
\text { scrap, waiting to report to the police; } \\
\text { 3.In order to control the cost and quality } \\
\text { of materials, it is need to monitor } \\
\text { materials input-output. }\end{array}$ \\
\hline \multirow{5}{*}{$\begin{array}{l}\text { Equipme } \\
\text { nt }\end{array}$} & $\begin{array}{l}\text { 1.Basic property } \\
\text { of equipment } \\
\text { 2.Equipment } \\
\text { running status }\end{array}$ & $\begin{array}{l}\text { 1.Monitoring can improve the } \\
\text { efficiency of production equipment; } \\
\text { 2.It can provide evidence for preparing } \\
\text { the reasonable production plan; } \\
\text { 3.Equipment monitoring is helpful to } \\
\text { make valuable maintenance plan. }\end{array}$ \\
\hline \multirow{5}{*}{ Workers } & $\begin{array}{l}\text { 1.Workers' } \\
\text { work condition } \\
\text { 2.Worker's } \\
\text { work type and } \\
\text { skills }\end{array}$ & $\begin{array}{l}\text { 1.Monitoring worker's condition can } \\
\text { prevented absenteeism and sabotage; } \\
\text { 2. Provide the basis for personnel } \\
\text { scheduling reasonably. }\end{array}$ \\
\hline
\end{tabular}

III. MONITORING SYSTEM'S INFORMATION TRANSFER

Manufacturing monitoring needs the support of information collection, transfer and expression technology. Next section 
will elaborate intelligent manufacturing information construction from two aspects: one is monitoring data collection and analysis; another one is workshop production information transfer.

\section{A. Process Monitoring Data Collection}

In the previous traditional mechanical production process, data collection mainly relied on manual or semi-manual mode, data transfer and dispose mainly relied on paper, both efficiency and accuracy of data-collection were relatively low. At the same time, it needed a lot of manpower and material resources to complete data gathering, processing, storage and query, and the data collected by this method had the obvious lagging, and even illusory. At present, the data collection of workshop line can be roughly divided into three types. First, getting the data directly from production equipment[2-3]. Second, data collection can use automatic identification technology. Third, pure manual mode or human-computer interaction mode.

Getting the data directly from production equipment can be able to complete data measurement, transmission and save rapidly, accurate, real-time. Accordingly it provide data support for statistical process quality control in the workshop in real time. But this way's demand for the more intelligent equipment is higher, this cause equipment structure complex, maintenance cost higher.

Automatic identification technology include bar code technology and RFID radio frequency identification technology, This kind of technology has advantages, such as simple manufacture scanning, data acquisition quick, large amount of storage data, the higher reliability of the data acquisition. At the same time, it can do in severe environment condition. But the technology is not widely used at present, the relative it is not yet mature.

Pure manual mode can collect a large number of different types of data, including numeric data and descriptive data. This method has the characteristics of simple, easy to operation. But large amounts of the artificial collection information are from the staff, and this greatly reduces the accuracy of data.

Every kind of information collection technology has its applicable occasions, in practical production, it needs to select suitable information acquisition methods based on corresponding situation and collection require, and so as to finish the build of information monitoring system.

\section{B. Transfer of Production Process Information}

The well-work of monitoring and control system need a important premise, the premise is collected monitoring information can be passed between decision-making departments and monitor objects. Present, workshop production information transfer method involve in traditional paper document or oral information transfer mode, LAN and the Internet transfer mode, short message between the base station and mobile terminal, and so on. Next paper elaborate those transfer method respectively.

1) Traditional paper document or oral transfer mode: In the traditional management mode, transfer of production information in workshop is paper document or oral transfer mode. And its flow is from the production locale problems found by workshop locale worker (include operator, quality inspection person, technical person and other related person), and then according to the seriousness of the problem and permissions of workers themselves to report production locale problems to superior leaders step by step through paper document or oral transfer mode. Traditional production process information transfer mode can not ensure the timeliness of information, and this kind of method also can not ensure the veracity of information.

2) Information transfer based on the LAN and the Internet: The LAN and internet provides favorable conditions for modern manufacturing plant internal link and transregional management. Workshop resource includes people, equipment and materials. The application of LAN technology in production and management of manufacturing workshop not only unify all kind of workshop locale resources as a whole, but also implement accurate and timely information communication between workshop site and management. Compared with traditional production information transfer methods, LAN and the Internet have many advantages, such as high accuracy, timely deliver, no regional restriction, and so on.

3) Message transmission based on base station and mobile terminal: Large manufacturing enterprise involving multiple disperse production field, enterprise need to master production operation condition under different time and different areas. The Internet can achieve the long-distance monitoring of the enterprise, but this method need the staff to monitoring information actively, but active monitoring easily cause the omission of production information and consequently cause the delay of the decision.

Information active push approach based on base station and mobile terminal can effectively solve the above problems. Base station will take the initiative to push information to the mobile terminal, it don't need allopatric management decision makers to read information actively, and second, short message service can judge whether message sent successful or failure, so it can ensure the validity of the information. Therefore, compared with the Internet, message transmission based on base station and mobile terminal has stronger practicability in the workshop production process monitoring. [5]

\section{Principle of Production Process Feedback Control}

The principle of negative feedback is adopted. The production process of object-controlled is monitored. The predetermined target is the target value of production plan. In order to realize the control of production process, the measuring mechanism is installed at the end of output, so as to test the output results and feed back to policy making. The policy decision is made after the policy making mechanism compares the output results with the target value, then the decision results is transferred to actuating mechanism. The control target achieves. It is illustrated in Figure I. 


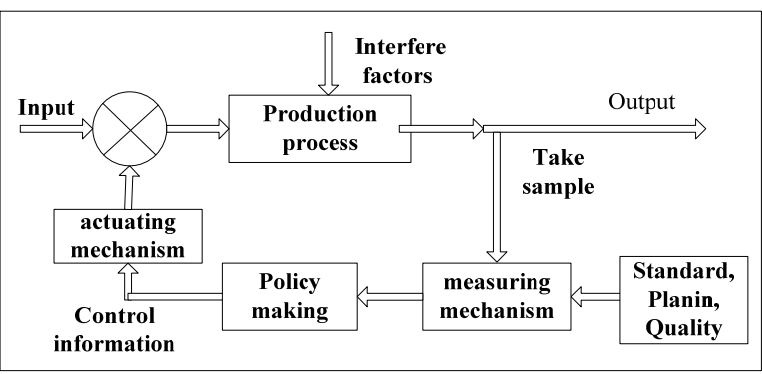

FIGURE I. PRINCIPLE OF PRODUCTION PROCESS FEEDBACK CONTROL

\section{Operation Mode Of Production Monitoring SYSTEM}

Based on above intelligent manufacturing monitoring system model, the section propose operation mode of intelligent manufacturing monitoring system based on MES, as shown in Figure II. The operation mode of production monitoring system based on MES using a repeated cycle negative feedback control principle, its special steps are as follows

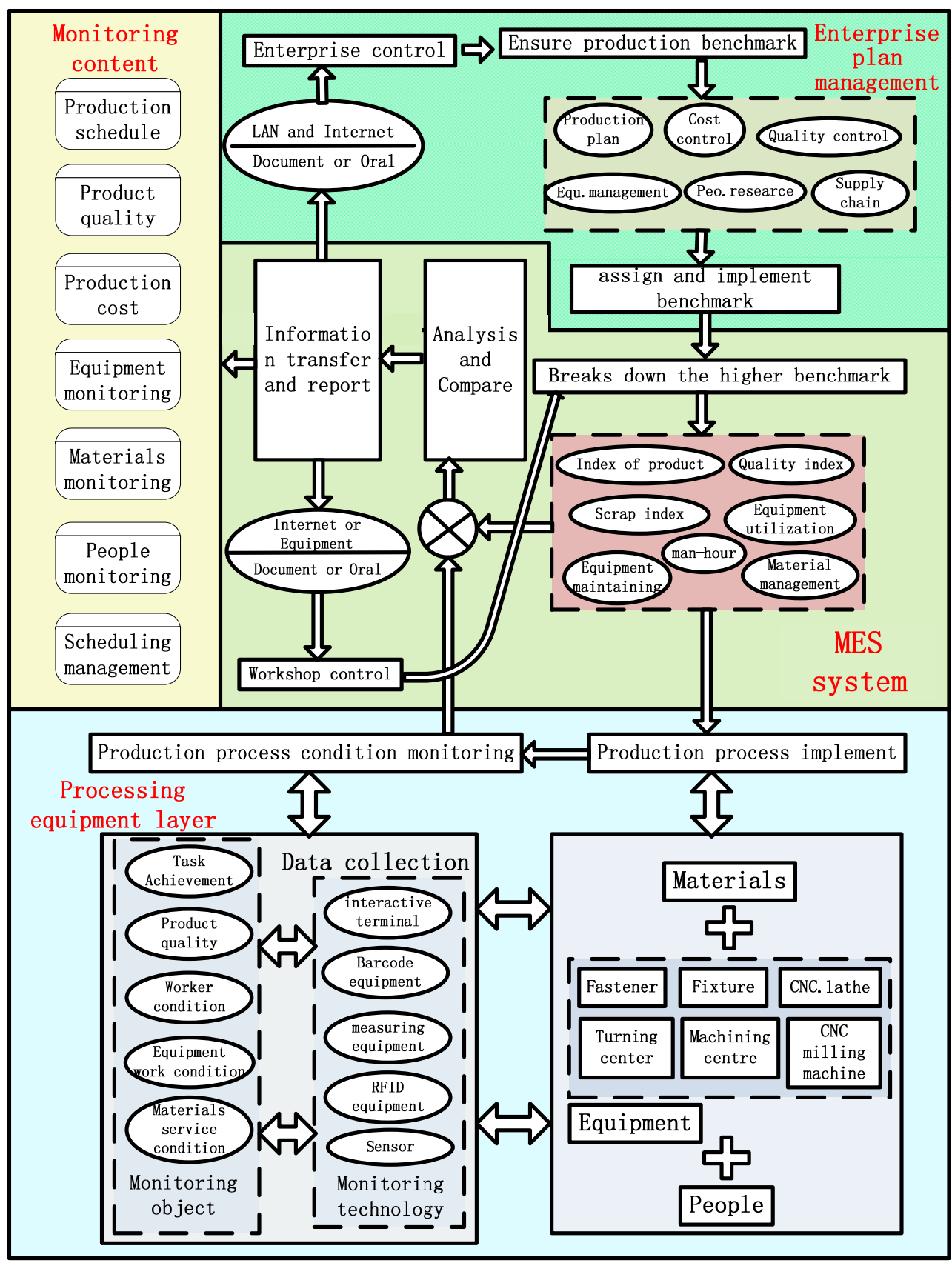

FIGURE II. OPERATION MODE OF INTELLIGENT MANUFACTURING PROCESS BASED ON MES 


\section{A. The Execution of the Benchmark in Production Process}

The benchmark in production process is important basis to make production process monitoring, it mainly include production plan, quality and process benchmark, equipment maintenance plan, manpower plan, cost control plan and materials supply chain planning, etc. Those plans are made by enterprise ERP. After the benchmark in production process is formulated by enterprise ERP, the benchmark is released to each production workshop. These plans must be clear, specific and practical.

\section{B. Breaks Down of the Higher Benchmark}

Workshop management will receive the production process benchmark formulated by superior through the MES, and then production process benchmark is further break down. For example, production planning is further subdivided into workshop's job plan and machining task. Process and quality benchmarks are further subdivided into percent of pass, rejection rate, process capability index, etc. Human resource planning benchmark could be subdivided into attendance rate, absence rate, work efficiency and staff working hours, and so on.

\section{The Implementation of the Production Process}

When management people finish the subdivision of each benchmark through MES, production plan are generated. Then, those plan need to be implemented by processing unit equipment layer in workshop, so this can realize the purpose of making the plan or indexes.

\section{Production Condition Monitoring and Analyze}

In order to ensure the execution of the benchmark in production process, it is necessary to monitor production schedule, product quality, equipment state, materials and worker condition, etc. This is fundamental source of monitoring data. Another aspect, monitoring technology uses RFID technology, barcode technology, sensor, humancomputer interaction techniques, and etc. After getting monitoring data, then compare the actual execution result with set benchmark. If there are errors, it needs to analyze the generation reason of errors, providing direction and basis for correcting deviation.

\section{E. Transfer and Control of Deviation Information}

After analyzing the generation reason of deviation, deviation information should be passed to enterprises workshop and upper personnel in charge timely through MES and Internet. People in charge will instantaneous analyze workshop production data, proposing the rectification method of error, and making it back to set benchmark level quickly.

\section{CONCLUSIONS}

In this paper, the model of monitoring information system of intelligent manufacturing is built. The model defines the entity object of monitoring system, expression method and transmission way of the monitoring information. The operation mode of monitoring system is proposed. Based on the model, it can provide the model basis for building actual monitoring information system of the enterprise, and serving intelligent manufacturing.

\section{ACKNOWLEDGMENT}

This work is supported by the scientific and technological innovation Program of Shanghai Municipal Education Commission (Program No. 15111102202).

\section{REFERENCES}

[1] Mai Yuanzhen. The Design and Implementation of Data Acquisition and Monitoring System for Discrete Manufacturing Industry[D].Guangdong university of technology, 2015. (In Chinese)

[2] Zhao Xudong. Study on data acquisition technique of CNC unit based on OPC [D]. University of electronic science and technology of china, 2015. (In Chinese)

[3] Zha, X.F.; Lim, S.Y.E.; Fok, S.C. Integration of knowledge-based systems and neural networks: Neuro-expert Petri net models and applications. In Proceedings of the 1998 IEEE International Conference on Robotics and Automation, Leuven, Belgium, 16-21 May 1998.

[4] Ke-Sheng Wang. Intelligent and integrated RFID (II -RFID) system for improving traceability in manufacturing [J].Advances in Manufacturing, 2014(2):106-120.

[5] Li, et al. / Front Inform Technology Electron Eng 2017, 18(1):86-96.

[6] PANG Jigjig. Path of green and intelligent manufacturing in the Internet[J]. Ecological Economy, 2015(3):277-286.

hong Qisheng, Chang Pingtang, Ci Xinglv. Modeling of Agile Intelligen Manufacturing-oriented Production Scheduling System[J]. International Journal of Automation and Computing, 2010(4):596-602. 